\title{
Advanced glycation end products and strontium ranelate promote osteogenic differentiation of vascular smooth muscle cells in vitro: Preventive role of vitamin D
}

\author{
María Silvina Molinuevo ${ }^{1}$, Juan Manuel Fernández ${ }^{1}$, Ana María Cortizo, \\ Antonio Desmond McCarthy, León Schurman, Claudia Sedlinsky* \\ Laboratorio de Investigación en Osteopatías y Metabolismo Mineral, Facultad de Ciencias Exactas, Universidad Nacional de La Plata. 47 y 115, (1900) La \\ Plata, Argentina
}

\section{A R T I C L E I N F O}

\section{Article history:}

Received 17 December 2016

Received in revised form

19 April 2017

Accepted 25 April 2017

Available online 26 April 2017

\section{Keywords:}

Advanced glycation end products

Vascular smooth muscle cells

Strontium ranelate

Osteoblasts

Vitamin D

\begin{abstract}
A B S T R A C T
Advanced glycation end products (AGE) have been demonstrated to induce the osteogenic transdifferentiation of vascular smooth muscle cells (VSMC). Strontium ranelate (SR) is an anti-osteoporotic agent that has both anti-catabolic and anabolic actions on bone tissue. However, in the last years SR has been associated with an increase of cardiovascular risk. We hypothesize that SR can increase the osteoblastic trans-differentiation of VSMC and the induction of extracellular calcifications, an effect that could be potentiated in the presence of AGE and inhibited by simultaneous administration of vitamin D. The present results of our in vitro experiments demonstrate that AGE and SR alone or in combination, stimulate L-type calcium channels, causing an increase in reactive oxygen species and activation of both ERK and NFkB, with the final effect of promoting the osteogenic shift of VSMC. Importantly, these in vitro effects of AGE and/or SR can be prevented by co-incubation with vitamin D.
\end{abstract}

(C) 2017 Elsevier B.V. All rights reserved.

\section{Introduction}

Osteoporosis is a highly prevalent condition, closely related to the aging process. The most common treatments for osteoporosis include oral supplementation with calcium and vitamin $\mathrm{D}$, and/or anti-osteoporotic drugs such as bisphosphonates, strontium ranelate (SR) or intermittent administration of rhPTH. In particular, SR is an interesting therapeutic option since it shows dual in vitro and in vivo anti-osteoporotic action: it decreases osteoclastic bone resorption while stimulating osteoblastic bone formation (Marie et al., 2011).

In order to select the best treatment option for an individual patient, it is important to investigate possible non-skeletal actions of these drugs or of their possible therapeutic combinations. For example, calcium supplementation on its own in patients with a negative balance of this cation (such as older adults) is controversial: several studies have found it to increase cardiovascular risk, although others have not (Bostick et al., 1999; Foley et al., 2008; Iso

\footnotetext{
* Corresponding author.

E-mail address: claudia.sedlinsky@gmail.com (C. Sedlinsky).

1 These authors contributed equally to this research.
}

et al., 1999). On the other hand, low serum levels of vitamin D that are prevalent in older adults have been associated with an increase both in cardiovascular risk, and in postural instability (and thus of bone fractures) (Body et al., 2012).

Osteoporosis as well as cardiovascular disease and diabetes may share some common pathophysiological mechanisms of disease such as the effects of accumulated advanced glycation end products (AGE) and the increase of intracellular oxidative stress that takes place after AGE interaction with its cognate receptor RAGE (Yan et al., 1994; McCarthy et al., 2013; Schmidt et al., 1994). We have previously demonstrated that AGE can induce a decrease in osteoblastic proliferation, differentiation and survival, and that these potentially deleterious effects for bone are prevented by SR (Fernandez et al., 2013). Regarding cardiovascular disease, AGE has been demonstrated to increase the proliferation and migration as well as osteogenic trans-differentiation of vascular smooth muscle cells (VSMC) following AGE-RAGE interaction (Suga et al., 2011; Ma et al., 2015). Thus, the effects of AGE on events leading to extracellular matrix calcification appear to be cell-type specific: antiosteogenic in the case of pre-osteoblasts, but pro-osteogenic for VSMC. Following this line of reasoning, the modulation by strontium of AGE-induced effects on mineralization could also be 
expected to be cell-type specific (preventive for bone-derived cells, the opposite for VSMC). Interestingly, it was demonstrated that physiological concentrations of vitamin D induce protective effects on vascular calcifications, whereas vitamin D deficiency is associated with an increase in vascular calcifications (McCarty and DiNicolantonio, 2014; Zimmermann et al., 2011).

Recently, SR has been claimed to increase cardiovascular risk, peripheral arterial disease, non-fatal myocardial infarction and venous thromboembolism, and its use was restricted by the European Medicine Agency (EMA 2013). Nevertheless, other communications have shown conflicting data regarding this issue. Svanström and coworkers showed in a nationwide cohort study of postmenopausal women in Denmark, using as a primary outcome acute coronary syndrome and as a secondary outcome any-cause mortality, that compared to the use of alendronate or risedronate, strontium ranelate was not associated with an increased risk of both end-points (Svanstrom et al., 2014). Another study by Cooper and coworkers using myocardial infarction, hospitalization with myocardial infarction, or cardiovascular death as primary outcome, was unable to find evidence for a higher risk for cardiac events associated with the use of strontium ranelate in postmenopausal osteoporosis (Cooper et al., 2014).

Since the actions of strontium may have similarities to those of extracellular calcium, we propose the following working hypothesis: strontium ranelate could increase the osteoblastic transdifferentiation of VSMC and thus the induction of extracellular calcifications, an effect that could be potentiated in the presence of AGE and inhibited by simultaneous coincubation with vitamin D. The aim of this study was to evaluate the in vitro effects of strontium ranelate on VSMC number, migration and transdifferentiation to the osteoblastic phenotype, with or without the influence of AGE, and to determine if vitamin D is able to modulate strontium ranelate and/or AGE effects on VSMC.

\section{Materials and methods}

\subsection{Preparation of advanced glycation end products}

Advanced glycation end product-modified bovine serum albumin (AGE) was prepared by incubation of $10 \mathrm{mg} / \mathrm{ml}$ bovine serum albumin (Sigma, Argentina) with $33 \mathrm{mM}$ d-glycolaldehyde in $150 \mathrm{mM}$ phosphate-buffered saline $\mathrm{pH} 7.4$ at $37^{\circ} \mathrm{C}$ for 3 days under sterile conditions after which unincorporated sugar was removed (Gangoiti et al., 2008). Control bovine serum albumin (BSA) was incubated in the same conditions without sugar. The formation of AGE was assessed with a Shimadzu spectrofluorometer by their characteristic fluorescence - emission maximum at $420 \mathrm{~nm}$ upon excitation at $340 \mathrm{~nm}$. The estimated level of AGE obtained by this in vitro incubation was $18.5 \%$ relative fluorescence units/mg protein, in contrast to $3.2 \%$ for control BSA.

\subsection{Isolation and incubation of vascular smooth muscle cells (VSMC)}

Adult male Sprague - Dawley rats (190-210 g) were maintained in a temperature - controlled room at $23^{\circ} \mathrm{C}$, with a fixed $12 \mathrm{~h}$ light: $12 \mathrm{~h}$ darkness cycle, and fed standard rat laboratory chow and water ad libitum. All experiments with animals were performed in conformity with the Guidelines on Handling and Training of Laboratory Animals published by the Universities Federation for Animals Welfare (Guide of TCaUoLA, 2011). Approval for animal studies was obtained from the institutional animal care committee (CICUAL approval number: 001-05-15). Animals were sacrificed by cervical dislocation under anesthesia and aortas were dissected.

VSMC were isolated from aorta rings as previously described
(Rodriguez et al., 2006). Briefly, tunica adventitia was dissected and the aorta cut into $1 \mathrm{~mm}$ rings. Individual rings were cultured in $25 \mathrm{~cm}^{2}$ flasks at $37{ }^{\circ} \mathrm{C}$ in a humidified incubator with an atmosphere of $95 \%$ air- $5 \% \mathrm{CO}_{2}$. Tissue explants were further cultured in DMEM containing 10\% fetal bovine serum (FBS) (Natocor, Cordoba, Argentina) and antibiotic-antimycotic products $(10,000 \mathrm{U} / \mathrm{ml}$ penicillin G sodium, 10,000 $\mu \mathrm{g} / \mathrm{ml}$ streptomycin sulfate, and $25 \mu \mathrm{g} /$ $\mathrm{ml}$ amphotericin B in $0.85 \%$ saline). The medium was changed initially after $24 \mathrm{~h}$ and then every $2-3 \mathrm{~d}$. After about 2-3 weeks, when cells had formed a confluent monolayer, they were harvested by addition of $0.05 \%$ trypsin, and the culture was continued using DMEM containing 10\% FBS. VSMC were characterized by expression of $\alpha$-actin.

For the different experiments, cells were seeded on multi-well plates and incubated in DMEM and $100 \mu \mathrm{g} / \mathrm{ml}$ of either BSA or AGE, with or without $0.1 \mathrm{mM}$ of strontium ranelate (SR, kindly provided by Institut de Recherches Internationales Servier). Alternatively, cells were cultured in absence or presence of $50 \mathrm{ng} / \mathrm{ml}$ of cholecalciferol (Vit D), $2.5 \mathrm{ng} / \mathrm{ml}$ calcitriol (1,25 Vit D), $10 \mu \mathrm{M}$ Nifedipine, Vitamins E and C (50 $\mu \mathrm{M}$ of each), $100 \mu \mathrm{M}$ of Sulfasalazine or $0.5 \mathrm{mM}$ of PD98059.

\subsection{Cell number studies}

A mitogenic bioassay was carried out as previously described (Okajima et al., 1992) with modifications. Briefly, VSMC were cultured in 24-well plates for 24 or 48 h submitted to different experimental conditions, after which they were washed with phosphate buffered saline (PBS) and fixed with 5\% glutaraldehyde/ PBS for $10 \mathrm{~min}$. Cells were stained with $0.5 \%$ crystal violet $(25 \%$ methanol) for $10 \mathrm{~min}$. Excess dye was discarded and the plate was extensively washed with water. The dye taken up by cells was extracted using $0.5 \mathrm{ml} /$ well $0.1 \mathrm{M}$ glycine/ $\mathrm{HCl}$ buffer, $\mathrm{pH} 3.0 / 30 \%$ methanol, which was transferred to test tubes and its absorbance read at $540 \mathrm{~nm}$. Correlation between the cell number and the absorbance at $540 \mathrm{~nm}$ has been previously established (Salice et al., 1999).

\subsection{Cell migration}

VSMC migration was assessed by an in vitro wound assay as previously described (Molinuevo et al., 2008). Confluent monolayers of VSMC were scratched (wounded) with a pipette tip. After washing with culture media, cells were incubated for an additional $12 \mathrm{~h}$ in DMEM-10\% FBS with either BSA or AGE, in the presence or absence of SR. After this incubation period, the monolayers were fixed and stained with Giemsa. Cell migration distance from the edge of the wound was assessed using the freeware Image J program (www.macbiophotonics.ca/imagej).

\subsection{Osteogenic differentiation}

Osteogenic induction of VSMC was performed by incubating confluent cell monolayers in DMEM-10\% FBS supplemented with $5 \mathrm{mM}$ b-glycerolphosphate and $25 \mu \mathrm{g} / \mathrm{ml}$ ascorbic acid. Under these culture conditions cells begin to secrete type 1 collagen, express alkaline phosphatase activity (ALP) and accumulate extracellular mineral deposits after 1 week, reaching a maximum after 2 weeks. For ALP determination, cells were washed with phosphate-buffered saline (PBS) and solubilized in $0.5 \mathrm{ml} 0.1 \%$ Triton $\times-100$. Aliquots of this total cell extract were used for protein determination (Bradford, 1976) and for measurement of ALP by spectrophotometric determination of initial rates of hydrolysis of $\mathrm{p}$-nitrophenylphosphate (p-NPP) to p-nitrophenol (p-NP) at $37^{\circ} \mathrm{C}$ for $10 \mathrm{~min}$. For evaluation of type 1 collagen production, cells were fixed with 
Bouin's solution and stained with Sirius red dye for $1 \mathrm{~h}$. The stained material was dissolved in $1 \mathrm{ml} 0.1 \mathrm{~N}$ sodium hydroxide and the absorbance of the solution was recorded at $550 \mathrm{~nm}$ (Fernandez et al., 2011). Accumulation of extracellular mineral deposits was evaluated by staining with Alizarin S Red, and quantitated spectrophotometrically at $540 \mathrm{~nm}$ after solubilization with $0.1 \mathrm{~N}$ sodium hydroxide (Fernandez et al., 2011).

\subsection{Western blot assays}

Cell monolayers were lysed with Laemmli's buffer (Laemmli, 1970). Total protein content of the cell lysates was evaluated by a micro-method (Lowry et al., 1951). Lysates were heated to $100{ }^{\circ} \mathrm{C}$ for $3 \mathrm{~min}$, after which aliquots containing $40 \mu \mathrm{g}$ of protein were subjected to $10 \%$ sodium dodecyl sulfate polyacrylamide gel electrophoresis. The separated proteins were then transferred to PVDF membranes (Millipore, Bedford, MD), which were blocked in 3\% non-fat dry milk in Tris-buffered saline (TBS) for $2 \mathrm{~h}$ at room temperature. They were then incubated at $4{ }^{\circ} \mathrm{C}$ for $24 \mathrm{~h}$ with antiRunx2(Santa Cruz Biotechnologies, sc-10758, Lot \#H1909), anti- $\alpha$ actin (Santa Cruz Biotechnologies, sc-53142, Lot \#H1909), or anti- $\beta$ actin polyclonal antibodies (Novus Biologicals, NB600-503, Lot \# A5) diluted 1:2000 in PBS with $0.5 \%$ bovine serum albumin. After four washes in PBS with $0.1 \%$ Tween 20 , the membranes were incubated with a secondary goat anti-rabbit antibody, followed by staining with the peroxidase-biotin reagent and diaminobenzidine from the Vectastain kit. The intensity of the Runx2, $\alpha$-actin and $\beta$ actin specific bands was quantified by densitometry after scanning the PVDF membrane with a Hewlett-Packard Scanjet 4C. Images were analysed using the gel plugin of Image J program (www. macbiophotonics.ca/imagej).

\subsection{Reactive oxygen species}

Stock solutions of dihydrorhodamine (DHR) (25 mM) and rhodamine123 (0.5 $\mathrm{mM})$ were prepared in nitrogen-purged dimethylformamide and stored in the dark at $-20^{\circ} \mathrm{C}$ until used (Cortizo et al., 2000). A fresh $10 \mathrm{mM}$ solution of DHR in DMEM was prepared every day. VSMC were incubated with AGEs, BSA and/or SR for $12 \mathrm{~h}$, after which the culture media was replaced by DHR in DMEM and cells were additionally incubated for an additional $4 \mathrm{~h}$ at $37^{\circ} \mathrm{C}$. VSMC monolayers were then washed twice with PBS and lysed with $1 \mathrm{ml}$ of $0.1 \%$ Triton $\times 100$. In the lysate, fluorescence intensity of the oxidized product rhodamine was determined (excitation wavelength, $495 \mathrm{~nm}$; emission wavelength, $532 \mathrm{~nm}$ ), using an Shimadzu RF-1500 spectrofluorometer. Fluorescence intensity was corrected for protein content (Bradford, 1976). A standard curve of rhodamine123 was constructed from 0.1 to $5 \mathrm{mM}$.

\subsection{Statistical analysis}

Three independent experiments were run for each experimental condition. Results are expressed as the mean \pm SEM. One Way ANOVA with Dunnett's post test was performed using GraphPad InStat version 3.05 GraphPad Software, San Diego, California USA. $\mathrm{P}<0.05$ was considered to be statistically significant.

\section{Results}

\subsection{Effects of AGE and/or SR treatment on VSMC number and migration}

In a first series of experiments we evaluated the effect of $100 \mu \mathrm{g} /$ $\mathrm{ml}$ AGE or BSA and/or $0.1 \mathrm{mM}$ SR on VSMC number. We found a significant increase in cell number after $48 \mathrm{~h}$ of AGE treatment
(A)

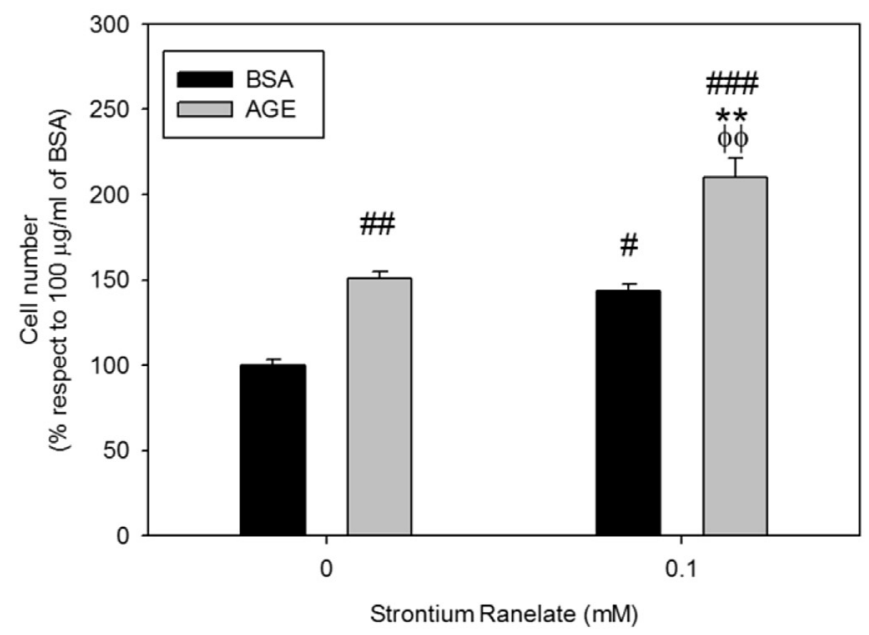

(B)

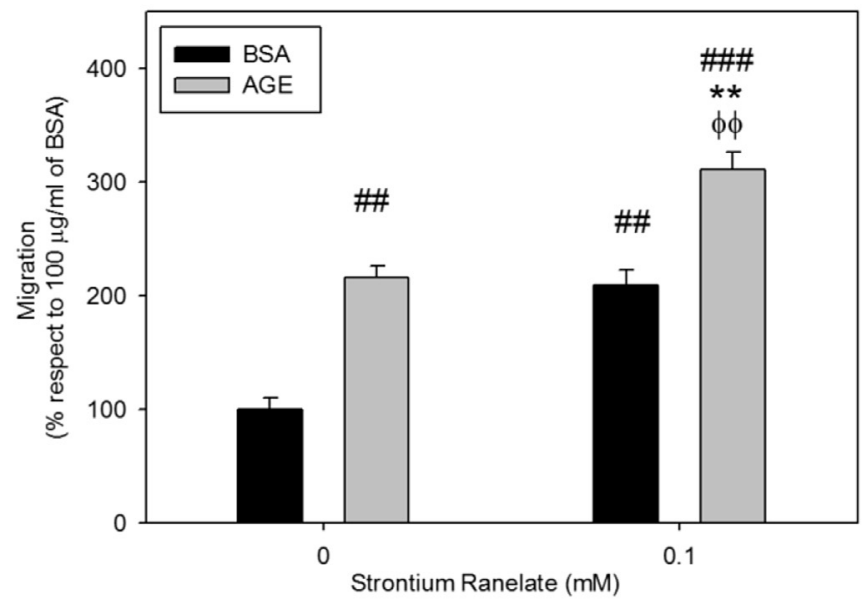

Fig. 1. Effect of AGE and/or SR on VSMC. (A) There is a significative increase on VSMC number caused by AGE or SR, while the co-incubation showed an additive stimulatory effect on cell proliferation. (B) AGE or SR promotes VSMC migration, with an additive effect in the co-incubation. Results are expressed as the mean + SEM, $n=8$. \#: $p<0.05$ vs. BSA; \#\#: $\mathrm{p}<0.01$ vs. BSA; \#\#\#: $\mathrm{p}<0.001$ vs. BSA; ** $\mathrm{p}<0.01$ vs. AGE; $\phi \phi: \mathrm{p}<0.01$ vs. BSA + SR

(Fig. 1A). On its own, SR also significantly increased VSMC number compared to BSA. Co-incubation of SR and AGE induced an additive increase in VSMC number (Fig. 1A). This increase in VSMC number caused by AGE and/or SR was completely prevented by treatment with either $10 \mu \mathrm{M}$ nifedipine (L-type calcium channel inhibitor), a mixture of vitamins $C$ and $\mathrm{E}$, oxidative stress inhibitors $(50 \mu \mathrm{M}$ of each), $100 \mu \mathrm{M}$ sulfasalazine (IKKS inhibitor, that prevents NFKB nuclear translocation), $50 \mathrm{ng} / \mathrm{ml}$ of vitamin D or $0.5 \mu \mathrm{M}$ PD 98,059 (a ERK kinase inhibitor) (Fig. 2A-E).

The migration ability of VSMC was evaluated using the scratch wound assay. We found that either AGE or SR significantly increased VSMC migration compared to BSA (Fig. 1B), and that coincubation of AGE with SR induced an additive effect. Again, the effect of both AGE and SR alone or in combination could be prevented by co-treatment with either nifedipine, a mixture of vitamins $\mathrm{E}$ and $\mathrm{C}$, sulfasalazine or vitamin D (Fig. 3A-D). 
(A)

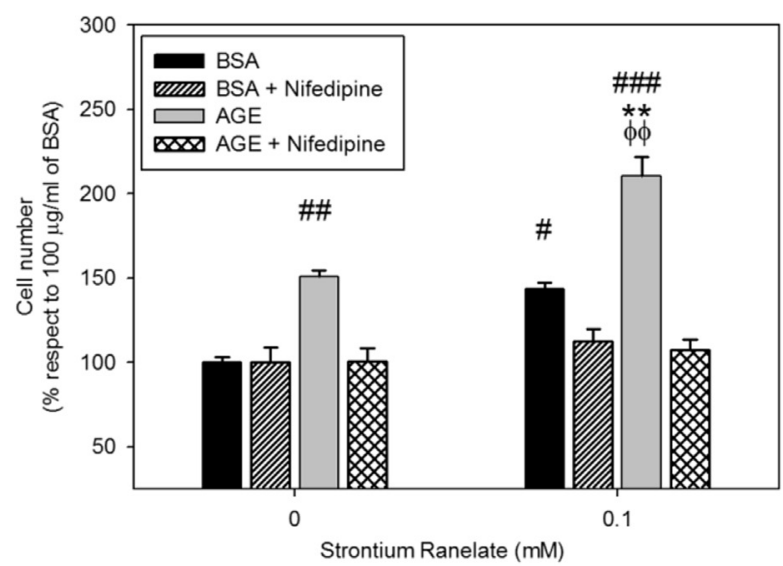

(B)

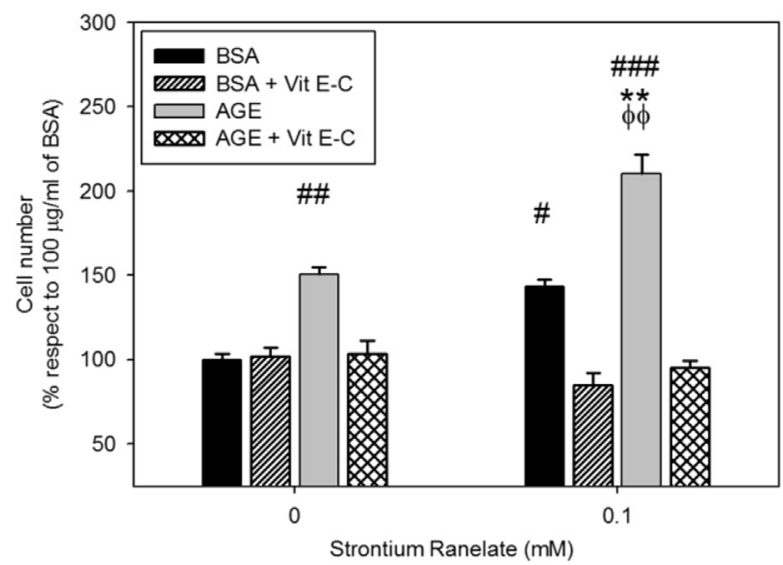

(C)

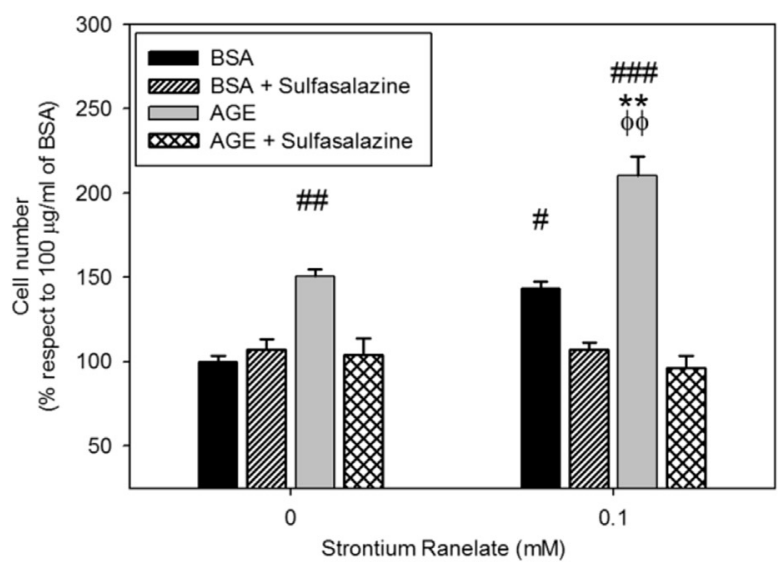

(D)

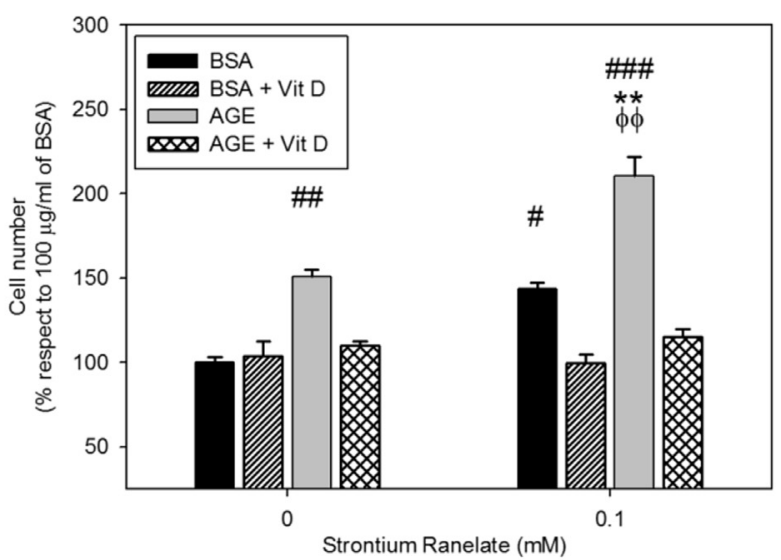

(E)

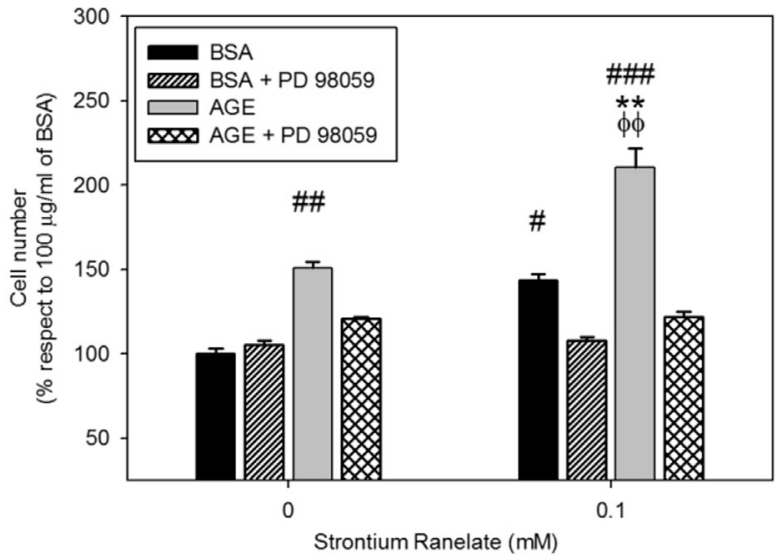

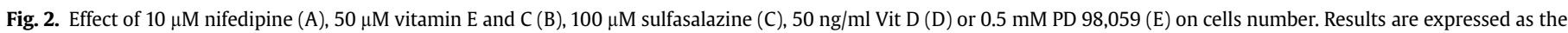
mean \pm SEM, $n=8$. \#: $p<0.05$ vs. BSA; \#\#: $p<0.01$ vs. BSA; \#\#\#: $p<0.001$ vs. BSA; ${ }^{* *}: p<0.01$ vs. AGE; $\phi \phi: p<0.01$ vs. BSA + SR.

\subsection{Effect of AGE and/or SR on VSMC osteogenic differentiation}

In additional experiments, we evaluated the effect of AGE and/or SR on the osteoblastic trans-differentiation of VSMC. We found that the addition of AGE to the osteogenic media caused an increase in collagen type I production (Fig. 4A), alkaline phosphatase activity (Fig. 4B) and extracellular mineral deposits (Fig. 4C) while it increased the expression of the osteogenic transcription factor 
(A)

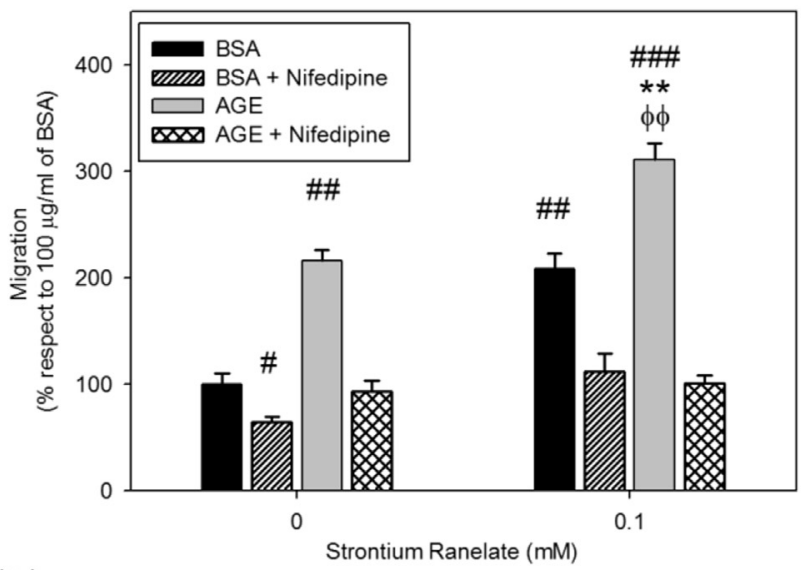

(B)

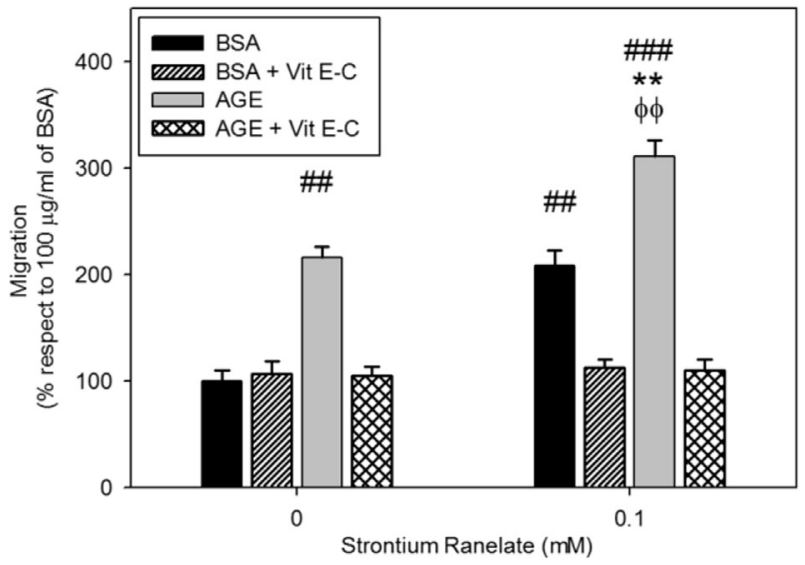

(C)

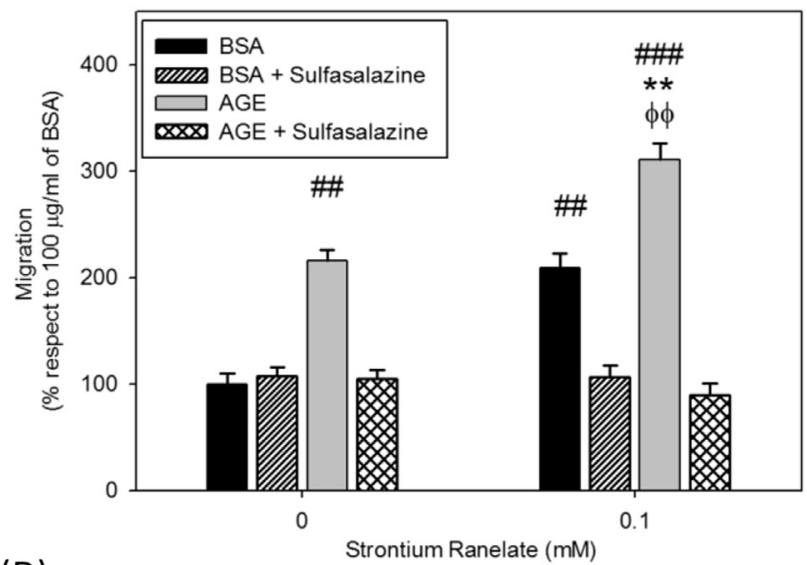

(D)

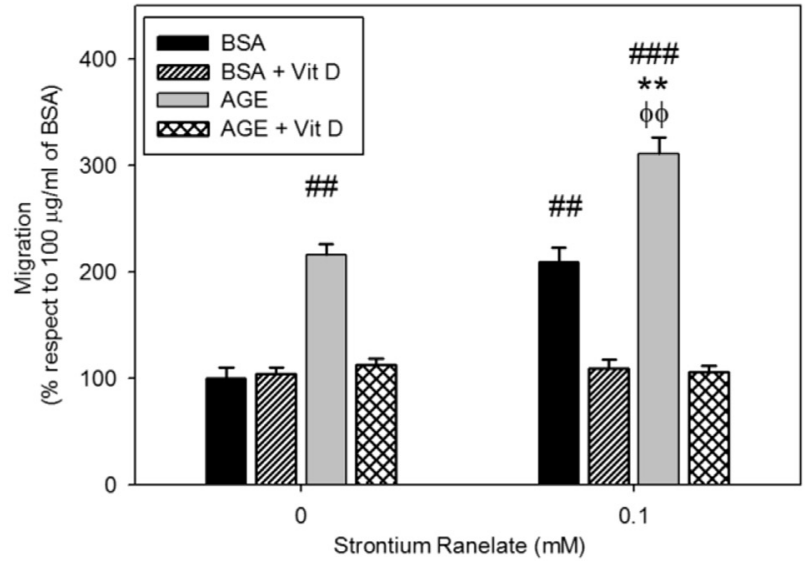

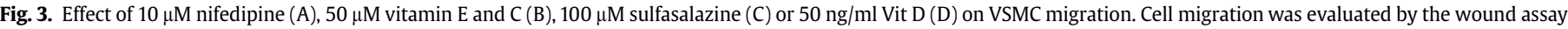

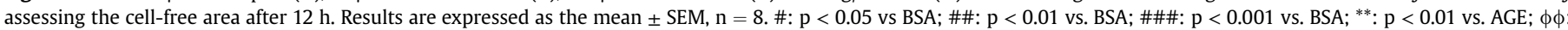
$\mathrm{p}<0.01$ vs. BSA + SR.

Runx2 (Fig. 5A) and inhibited the expression of $\alpha$-actin, a marker of VSMC phenotype (Fig. 5B). Similarly, SR on its own also caused VSMC to increase their production of collagen and extracellular mineral deposits, to stimulate alkaline phosphatase activity (Fig. 4) and to increase Runx2 expression while decreasing $\alpha$-actin expression (Fig. 5). SR co-incubated with AGE caused an additive effect on the induction of osteogenic parameters and in the decrease of VSMC phenotypic markers (Figs. 4 and 5). Proosteogenic effects induced by AGE and/or SR, evaluated by the type 1 collagen secretion, could be prevented by co-incubation with either nifedipine, a mixture of vitamins $E$ and $C$, sulfasalazine or PD98059 (Fig. 6A-D). Similar preventive effects of AGE and/or SR pro-osteogenic action were observed both for vitamin $\mathrm{D}$ (cholecalciferol) and for $1,25(\mathrm{OH})_{2}$-vitamin D (calcitriol) (Fig. 6E). In addition, vitamin $\mathrm{D}$ also prevented the stimulation of Runx2 expression (Fig. 6F) and extracellular mineral deposits induced by AGE and/or SR (Fig. 6G).

3.3. Role of intracellular oxidative stress on the osteogenic actions of $A G E$ and/or $S R$

In order to investigate the role of oxidative stress on the actions of AGE, SR or their combination, we measured their effect on production by VSMC of intracellular reactive oxygen species (ROS). We found that $100 \mu \mathrm{g} / \mathrm{ml}$ of AGE caused a significant increase in ROS production compared to BSA (Fig. 7A). SR also increased ROS production, while co-incubation of SR with AGE induced an additive effect (Fig. 7A). Nifedipine, vitamin D or a mixture of vitamins $C$ and $E$ completely prevented the increase in ROS production induced by AGE and/or SR (Fig. 7B-D). Similar preventive effects were observed for calcitriol (data not shown). On the other hand, coincubation with sulfasalazine did not prevent AGE and/or SRinduced ROS production (Fig. 7E).

\section{Discussion}

In the present work we evaluated the osteogenic transdifferentiation of VSMC after co-incubation with BSA or AGE and/ or SR, and its possible modulation with vitamin D. One of the first steps for transition from myocytic to osteogenic phenotype is an increase in cellular secretory, proliferative and migratory capacity (Owens et al., 2004). In our experiments with VSMC, we found an AGE-induced increase in cell number and migration (compared to BSA). On the other hand, other authors described that AGEs can also induce apoptosis on VSMC involving oxidative stress mechanisms (Koike et al., 2016). Additionally, and in agreement with the previous research of other authors, we found an AGE-induced increase in the expression of osteogenic phenotype markers (alkaline 
(A)

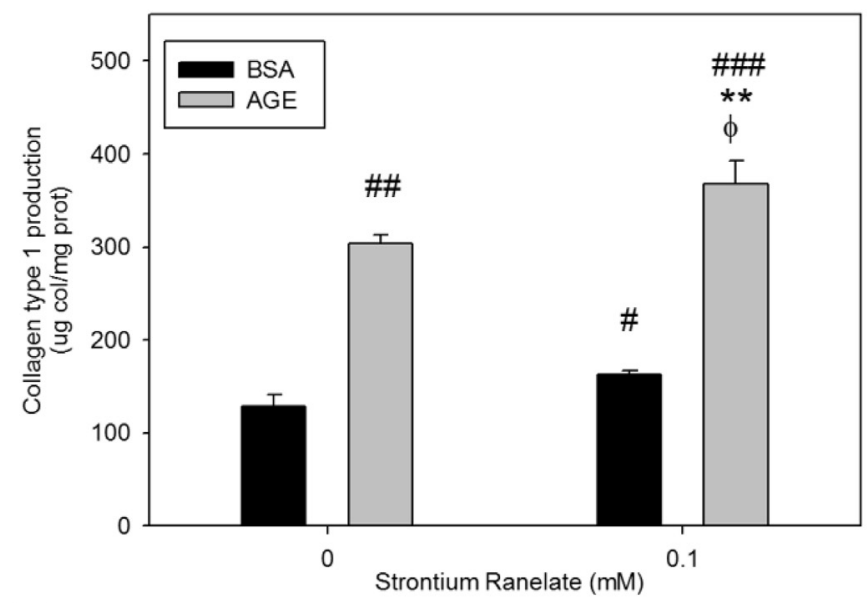

(B)
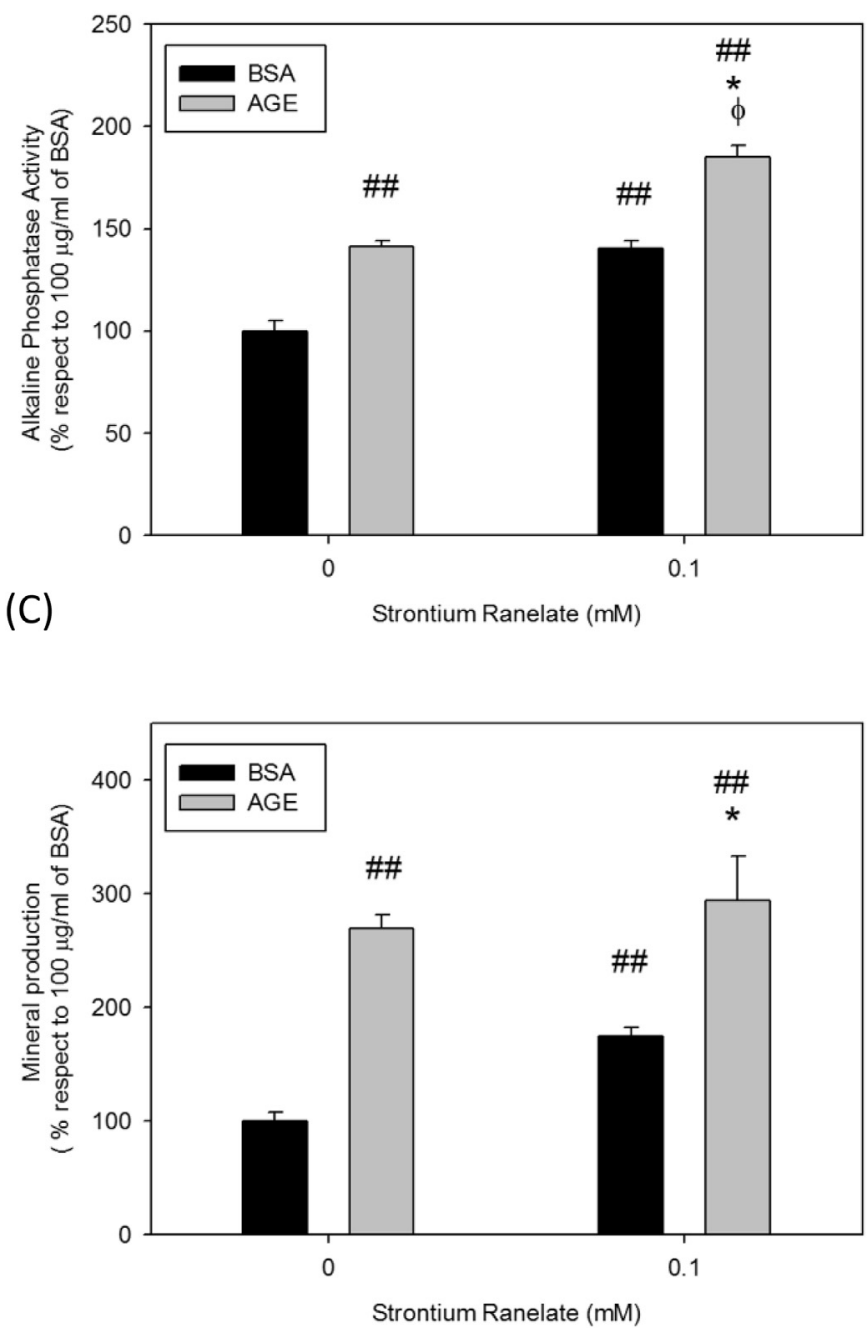

Fig. 4. Effect of AGE and/or SR on osteogenic differentiation of VSMC. Osteoblastic differentiation was evaluated as collagen type 1 expression (A), alkaline phosphatase activity (B) and calcium nodules (mineral, C). Results are expressed as the mean \pm SEM, $\mathrm{n}=8$. \#: $\mathrm{p}<0.05$ vs. BSA; \#\#: $\mathrm{p}<0.01$ vs. BSA; \#\#\#: $\mathrm{p}<0.001$ vs. BSA; *: $\mathrm{p}<0.05$ vs. AGE; ${ }^{* *}: \mathrm{p}<0.01$ vs. AGE; $\phi: \mathrm{p}<0.05$ vs. BSA + SR.
(A)

Runx 2
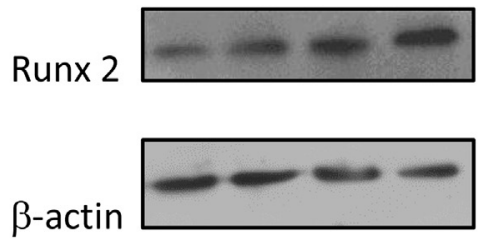

$\begin{array}{llll}1 & 2 & 3 & 4\end{array}$

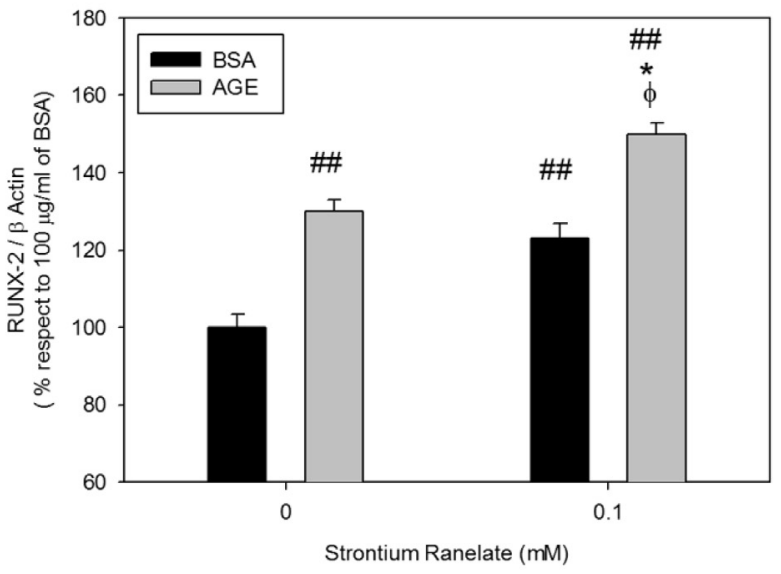

(B)
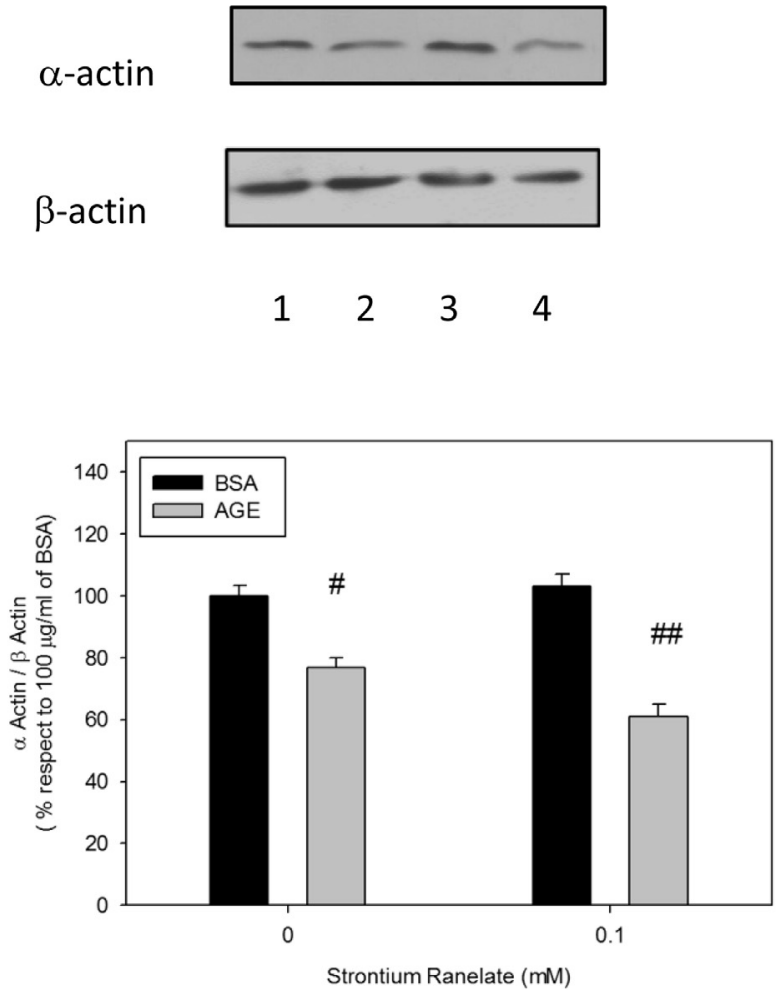

Fig. 5. Effect of AGE and/or SR on the expression of the osteogenic marker Runx2 (A) and the miogenic marker $\alpha$-actin (B). Western blot lanes: 1-BSA, 2-AGE, 3-BSA + SR, 4AGE + SR. Results are expressed as the mean \pm SEM, $\mathrm{n}=8$. \#: $\mathrm{p}<0.05$ vs. BSA; \#\#: $\mathrm{p}<0.01$ vs. BSA; *: $\mathrm{p}<0.05$ vs. AGE; $\phi: \mathrm{p}<0.05$ vs. BSA + SR.

phosphatase activity, type 1 collagen secretion, mineral nodule formation, Runx2/ $\beta$-actin ratio) (Ren et al., 2009; Tanikawa et al., 2009; Wang et al., 2003). Although those authors described pro- 
(A)

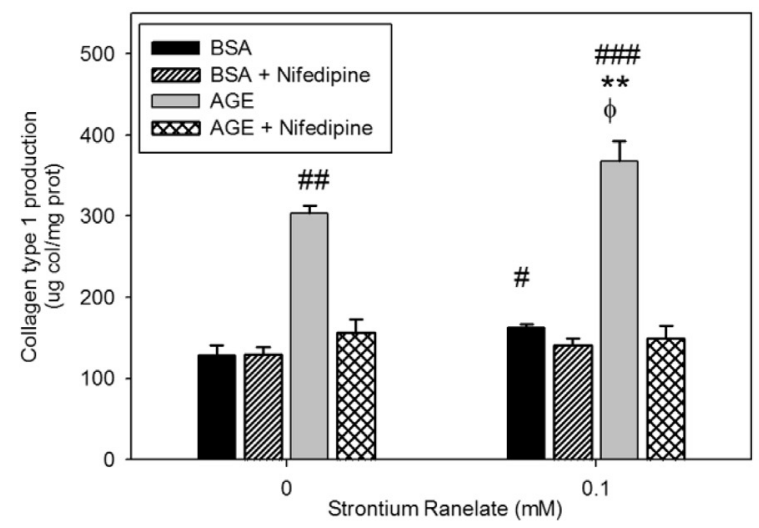

(B)

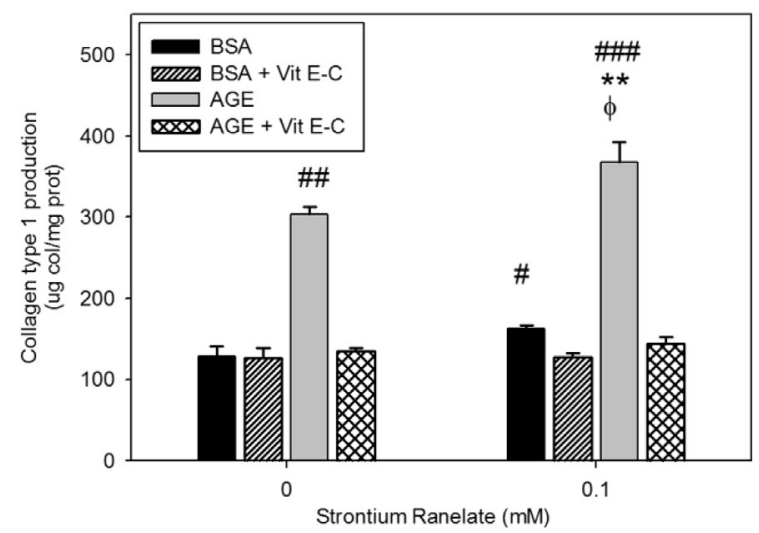

(C)

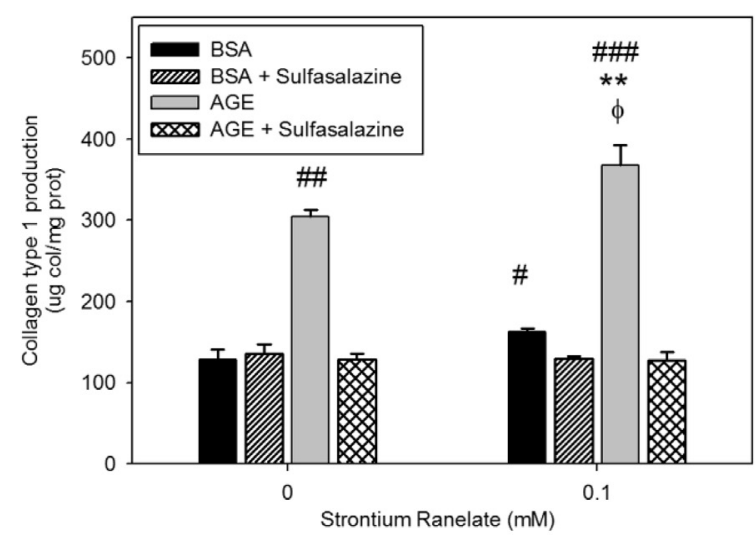

(D)

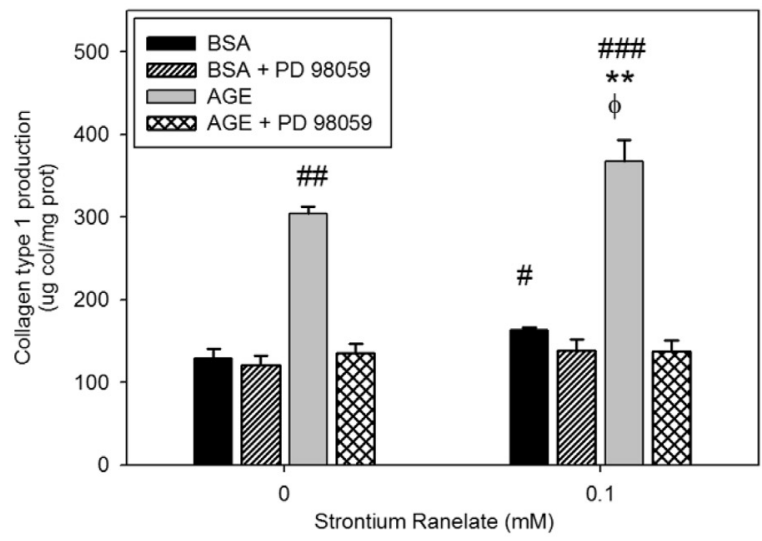

(E)

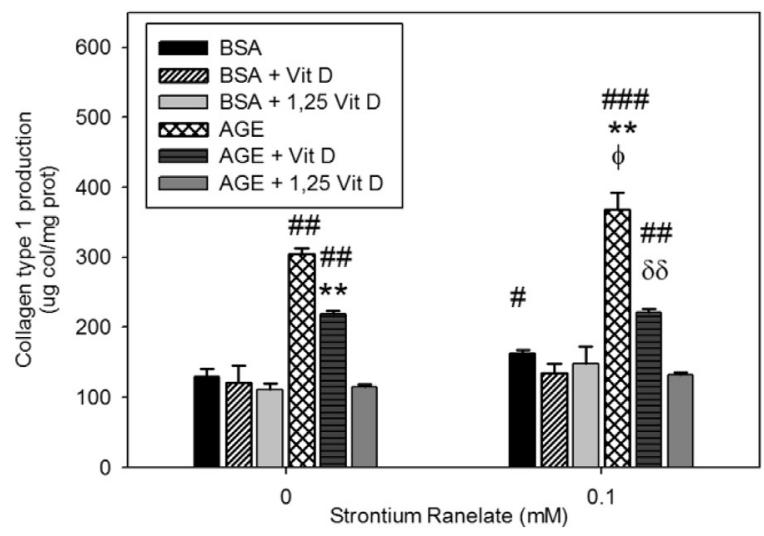

(F) Runx2

$\beta$-actin
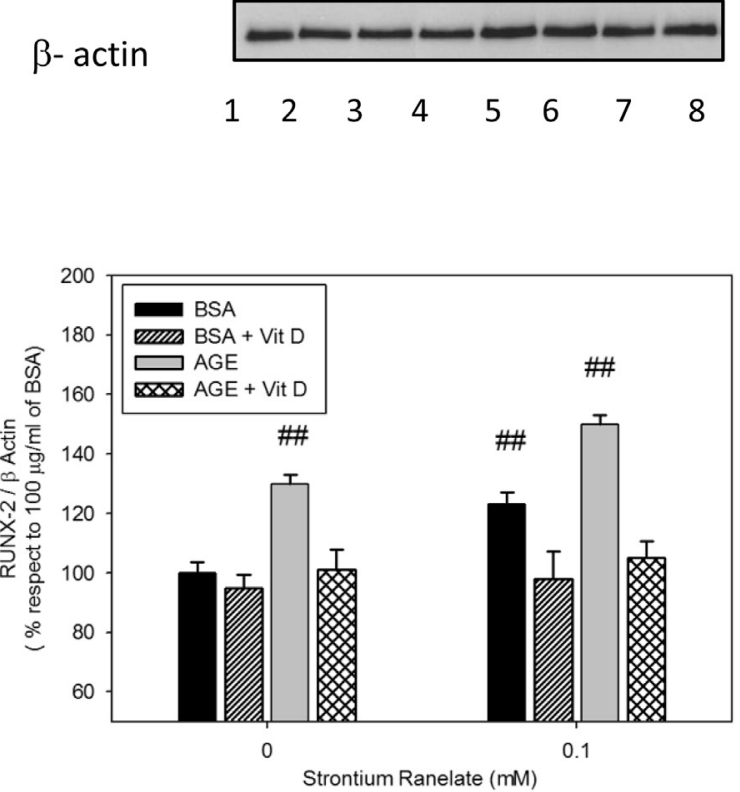

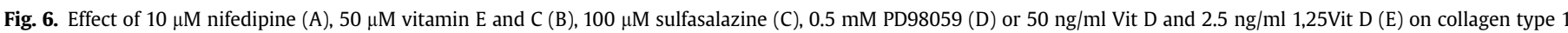

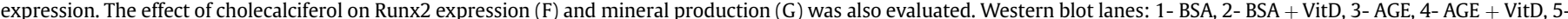

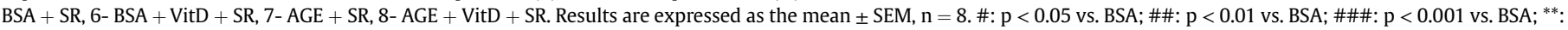
$\mathrm{p}<0.01$ vs. AGE; $\phi: \mathrm{p}<0.05$ vs. BSA + SR; $\delta \delta: \mathrm{p}<0.01 \mathrm{vs}$. AGE + SR. 
(G)

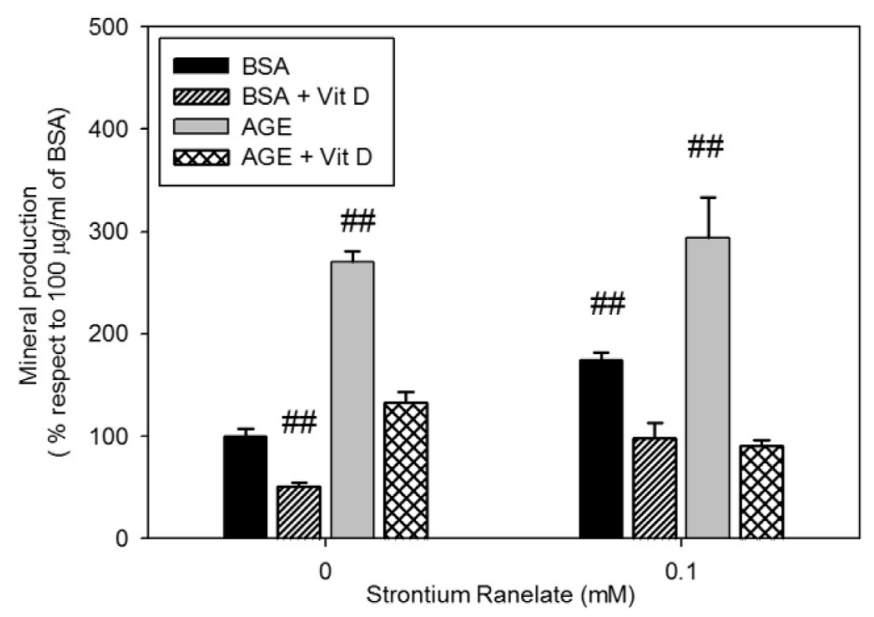

Fig. 6. (continued)

osteogenic actions of AGE on VSMC, none evaluated the decrease of $\alpha$-actin as a marker of smooth muscle phenotype. In our present work, we demonstrate that exposure of VSMC to AGE induces loss of $\alpha$-actin and acquisition of osteoblastic genes. Other authors previously demonstrated that VSMC lose their myocytic phenotype as they trans-differentiate to osteoblasts (Steitz et al., 2001). In particular they showed that induction of vascular calcifications was concomitant with loss of smooth muscle $\alpha$-actin and smooth muscle 22alpha expression, and with gain of osteopontin expression both in vitro and in vivo. On the other hand, we have previously demonstrated that extracellular matrix mineralization is impaired in vitro and in vivo in the presence of AGE, as well as in pathological conditions where AGE accumulates such as diabetes or the metabolic syndrome (Cortizo et al., 2003; Felice et al., 2012; McCarthy et al., 1997, 1999, 2001a,b; Mercer et al., 2004; Tolosa et al., 2013). These apparently opposing effects of AGE (anti-osteogenic for bone cells, pro-osteogenic for VSMC), are in fact supported by several population studies that point out the coexistence of bone loss with calcifications of the aortic tunica media. Although the molecular mechanisms that regulate this phenomenon are incompletely known, it has been suggested that AGE plays an important role in this process (Campos-Obando et al., 2015; Kiel et al., 2001). Previous studies have demonstrated that both in VSMC and in osteoblasts AGE interact with its receptor RAGE which in turns activates intracellular signals that activate proinflammatory genes responsible of its effects on these cells (Suga et al., 2011; McCarty and DiNicolantonio, 2014; Cortizo et al., 2003; McCarthy et al., 1999; Mercer et al., 2004; Menini et al., 2013).

Strontium ranelate (SR) has been approved for treatment of postmenopausal osteoporosis. However, in 2014 the European Medicine Agency (EMA) restricted the use of SR because its concern about associated cardiovascular risk (peripheral thrombosis, cerebral and myocardial infarction). Two retrospective studies have proposed to restrict the use of SR in patients with previous cardiovascular events of any type (Abrahamsen et al., 2014; Yu et al., 2015). To date, there are no reports evaluating possible mechanisms for the incidence of cardiovascular events in patients treated with SR.

Our present results demonstrate that SR induces VSMC to accumulate extracellular mineral in vitro, and that SR also causes an additive effect on mineralization when it is co-incubated with AGE.
Furthermore we show that the actions of SR on VSMC can be prevented by sulfasalazine and nifedipine, suggesting that in this cell type SR stimulates the pro-inflammatory pathway of NFkB by activating the L-type calcium channels. The effect of a structurally related analogous of nifedipine, lacidipine, on the process of atherogenesis was demonstrated long time ago. Paoletti et al., showed that this calcium antagonist inhibit cholesteryl ester metabolism in macrophages, and proliferation and migration of myocytes (Paoletti et al., 1996). In the present study, we show that the addition of vitamin $\mathrm{E}+\mathrm{C}$ to the VSMC cultures prevented the deleterious effects of both AGE and SR on VSMC number (Fig. 2B), migration (Fig. 3B) and osteoblastic differentiation (Fig. 6B) probably counteracting the effects of oxidative stress on these cells (Fig. 7C). It has been previously demonstrated that vitamin C provides protection against oxidative stress-induced cellular damage by scavenging of reactive oxygen species. Vitamin E functions as an essential lipid soluble antioxidant, scavenging hydroperoxylradicals in the lipid milieu. Vitamin E reacts rapidly with peroxyl radicals to form the corresponding lipid hydroperoxide and the tocopheryl radical. The tocopheryl radical reacts with vitamin C; thus, vitamin C is oxidated and vitamin E returns to its reduced state enabling it to continue scavenging oxidized radicals (vitamin E recycling). In our study, we show that different doses of ascorbic acid (vitamin C) can either induce osteoblastic differentiation of VSMC in vitro and ex vivo $(25 \mu \mathrm{g} / \mathrm{mL}$ during 15 days of vitamin $\mathrm{C}$ alone), or reverse the effects of AGE on collagen type 1 production by VSMC $(8.5 \mu \mathrm{g} / \mathrm{mL}$ of vitamin $\mathrm{C}$ as an additive for vitamin $\mathrm{E}$ recycling) (Traber and Stevens, 2011).

However it is not clear from our present study if SR enters VSMC via L-type calcium channels, or simply activates them. In any case, we show that activation of these channels increases intracellular ROS (Fig. 7) and thus promotes NFkB, which finally leads to an increase in the proliferative, migratory and pro-osteogenic capacity of these cells. It has been previously pointed out that oxidative stress drives the osteoblastic trans-differentiation of VSMC (McCarty and DiNicolantonio, 2014). Intracellular ROS production can also be increased by binding of AGE to its cognate receptor RAGE (McCarthy et al., 2001a): thus it is not unexpected to find that both AGE and SR promote the osteogenic induction of VSMC, showing an additive effect when they are co-incubated. Both agents could have the final result of potentiating activation of the NFkB pathway 
(A)

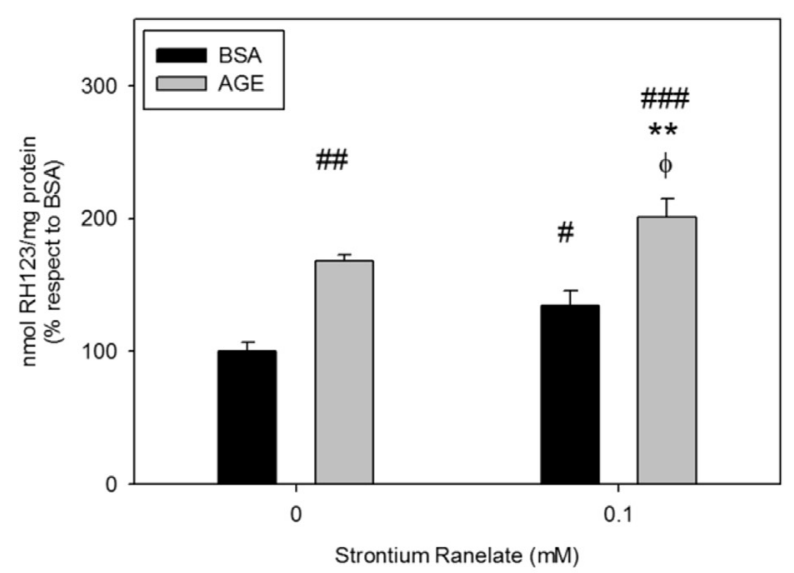

(B)

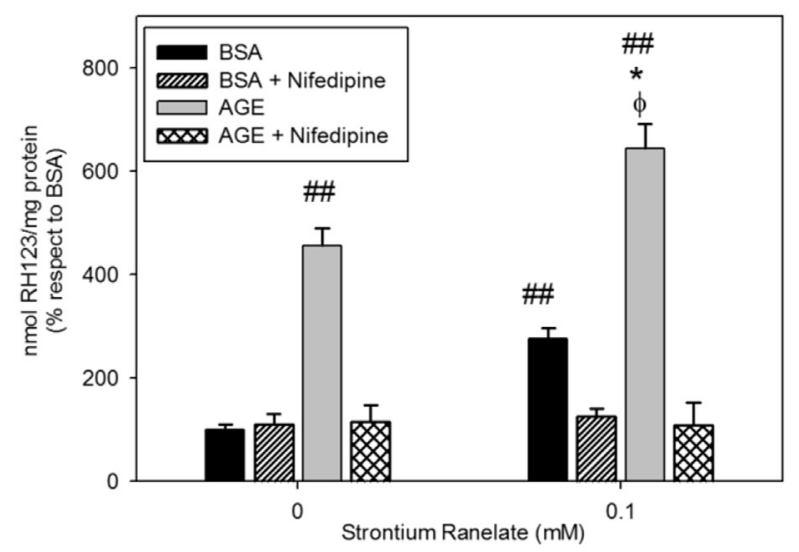

(C)

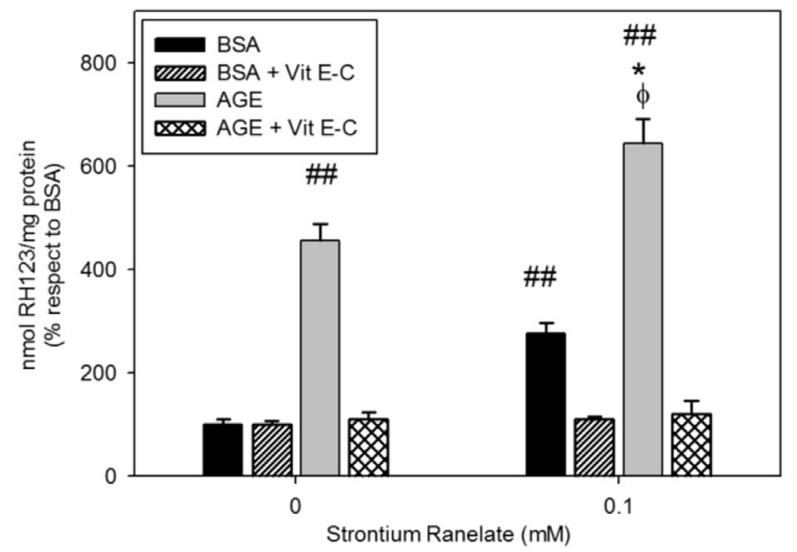

(D)

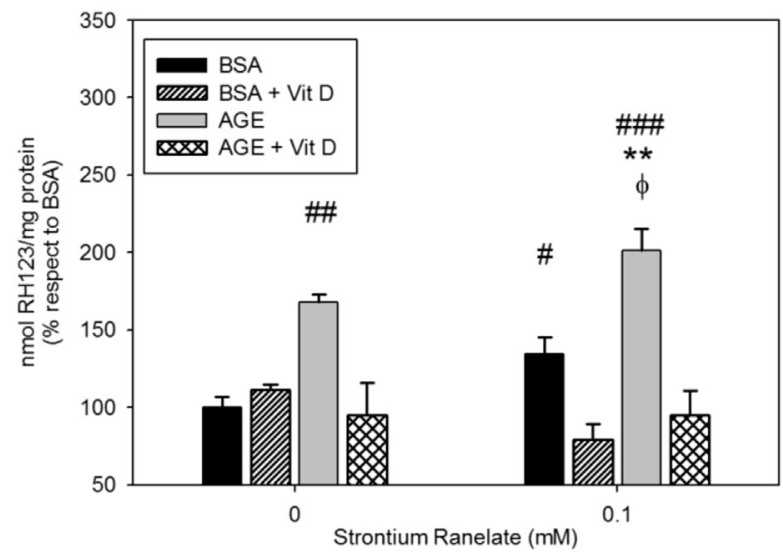

(E)

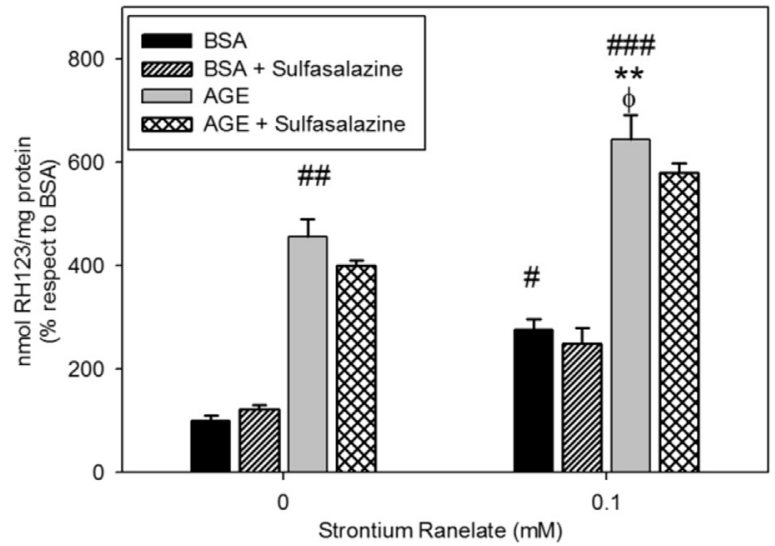

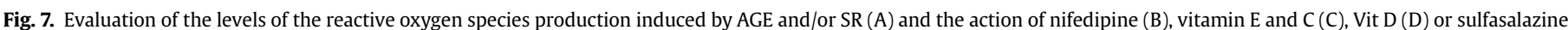
(E). Results are expressed as the mean \pm SEM, $n=8$. \#: $p<0.05$ vs. BSA; \#\#: $p<0.01$ vs. BSA; \#\#\#: $p<0.001$ vs. BSA; **: $p<0.01$ vs. AGE; $\phi$ : $p<0.05$ vs. BSA + SR.

(Fig. 8).

Our present results with VSMC differ from those previously reported by our group with osteoblasts in culture (Fernandez et al., 2013). In our previous work, we found that SR prevented the deleterious actions of AGE on osteoblasts in culture by activation of L-type calcium channels and a decrease in the secretion of proinflammatory cytokines. We have yet to elucidate the molecular reasons for these divergent effects; however, these results highlight 

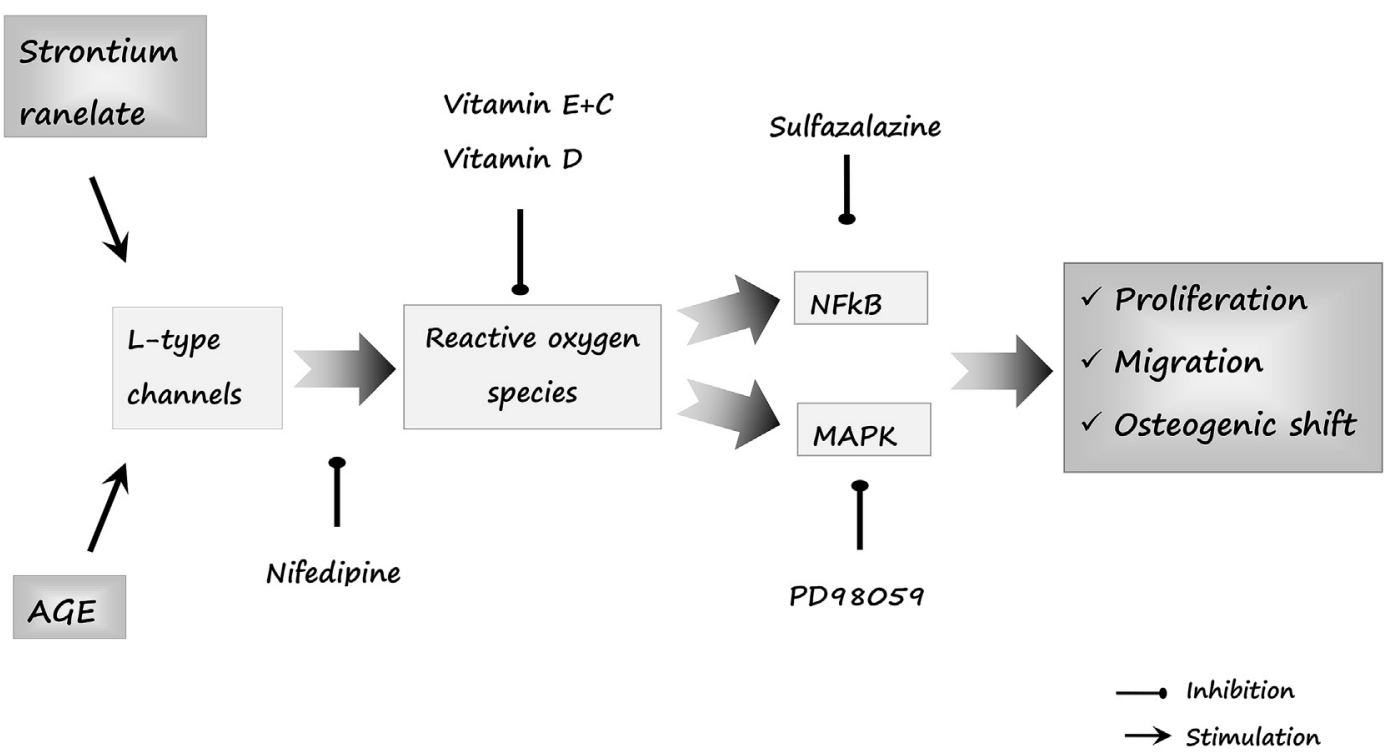

Fig. 8. Proposed mechanism of action of AGE on vascular smooth muscle cells osteoblastic trans-differentiation.

the fact that the specific effect of SR in the context of AGE accumulation depends on the cell system under study.

In order to investigate the possible mechanism of action of AGEs and SR on VSMC, we assessed the signalling to ERK pathway. The AGE and/or SR-induced number of cells (Fig. 2E) and type 1 collagen production (Fig. 6D) were totally blocked by PD98058, thus suggestion that ERK phosphorylation could be involved in the osteogenic trans-differentiation effects of both, AGE and SR. These results agree with our previous observations that the anabolic action of strontium ranelate on osteoblasts is mediated by the activation of ERK pathway (Fernandez et al., 2013).

In our present study, we have also demonstrated that vitamin D (cholecalciferol) modulates the osteogenic trans-differentiation of VSMC in response to AGE and/or SR. Indeed, we found that the osteogenic differentiation of VSMC was blunted when the cells exposed to AGE and/or SR were co-incubated with vitamin D. Moreover, we found that vitamin D exerted an antioxidant effect and this could be associated with the prevention of Runx2 upregulation. VSMC have been previously demonstrated to express 25 - and $1 \alpha$-hydroxylases, suggesting that these cells can metabolize either cholecalciferol or calcidiol (Somjen et al., 2005; Jia et al., 2016). Additionally, anti-inflammatory properties of 1,25 -vitamin D (calcitriol) have been reported in VSMC (Tukaj et al., 2012). It was recently demonstrated that calcitriol prevented in vitro VSMCs mineralization by regulating calcium-sensing receptor expression (Mary et al., 2015). This evidence points to a significant and protective role of vitamin $\mathrm{D}$ on the vasculature.

Additionally, our results show in an in vitro model a reversion of SR pro-osteogenic effects on VSMC differentiation by co-treatment with vitamin D. However, we cannot extrapolate these results to humans. Further clinical investigations are needed to prove that this drug association has similar effects in human patients.

In conclusion, we have demonstrated in vitro that AGE and SR alone or in combination, stimulate L-type calcium channels, induce an increase in reactive oxygen species, in NFkB signalling pathway and in ERK activation, promoting an osteogenic shift of VSMC (Fig. 8). In addition, that these effects of AGE and/or SR can be prevented by co-incubation with vitamin $\mathrm{D}$.

\section{Conflict of interest}

All authors declare that they have no conflict of interest.

\section{Acknowledgements}

JMF and MSM are members of Carrera del Investigador (CONICET), Argentina. AMC is members of Carrera del Investigadorof CICPBA, Argentina. ADM is part time Professor of Anatomy and Histology at National University of La Plata (UNLP). Financial support for this study was provided by CONICET (PIP2014), CICPBA, ANPCyT (PICT 2012-0053) and UNLP (11/X643).

\section{References}

Abrahamsen, B., Grove, E.L., Vestergaard, P., 2014. Nationwide registry-based analysis of cardiovascular risk factors and adverse outcomes in patients treated with strontium ranelate. Osteoporos. Int. 25, 757-762.

Body, J.J., Bergmann, P., Boonen, S., Devogelaer, J.P., Gielen, E., Goemaere, S., Kaufman, J.M., Rozenberg, S., Reginster, J.Y., 2012. Extraskeletal benefits and risks of calcium, vitamin D and anti-osteoporosis medications. Osteoporos. Int. 23 (Suppl. 1), S1-S23.

Bostick, R.M., Kushi, L.H., Wu, Y., Meyer, K.A., Sellers, T.A., Folsom, A.R., 1999. Relation of calcium, vitamin d, and dairy food intake to ischemic heart disease mortality among postmenopausal women. Am. J. Epidemiol. 149, 151-161.

Bradford, M.M., 1976. A rapid and sensitive method for the quantitation of microgram quantities of protein utilizing the principle of protein-dye binding. Anal. Biochem. 72, 248-254.

Campos-Obando, N., Kavousi, M., Roeters van Lennep, J.E., Rivadeneira, F., Hofman, A., Uitterlinden, A.G., Franco, O.H., Zillikens, M.C., 2015. Bone health and coronary artery calcification: the rotterdam study. Atherosclerosis 241, $278-283$.

Cooper, C., Fox, K.M., Borer, J.S., 2014. Ischaemic cardiac events and use of strontium ranelate in postmenopausal osteoporosis: a nested case-control study in the cprd. Osteoporos. Int. 25, 737-745.

Cortizo, A.M., Bruzzone, L., Molinuevo, S., Etcheverry, S.B., 2000. A possible role of oxidative stress in the vanadium-induced cytotoxicity in the MC3T3E1 osteoblast and UMR106 osteosarcoma cell lines. Toxicology 147, 89-99.

Cortizo, A.M., Lettieri, M.G., Barrio, D.A., Mercer, N., Etcheverry, S.B., McCarthy, A.D., 2003. Advanced glycation end-products (AGEs) induce concerted changes in the osteoblastic expression of their receptor rage and in the activation of extracellular signal-regulated kinases (erk). Mol. Cell Biochem. 250, 1-10.

Felice, J.I., McCarthy, A.D., Cortizo, A.M., 2012. Histomorphometric analysis of diabetic bone disease in rat models. Arch. Osteoporos. 7, S183.

Fernandez, J.M., Molinuevo, M.S., Cortizo, M.S., Cortizo, A.M., 2011. Development of an osteoconductive PCL-PDIPF-hydroxyapatite composite scaffold for bone tissue engineering. J. Tissue Eng. Regen. Med. 5, e126-135.

Fernandez, J.M., Molinuevo, M.S., Sedlinsky, C., Schurman, L., Cortizo, A.M., McCarthy, A.D., 2013. Strontium ranelate prevents the deleterious action of advanced glycation end-products on osteoblastic cells via calcium channel activation. Eur. J. Pharmacol. 706, 41-47.

Foley, R.N., Collins, A.J., Ishani, A., Kalra, P.A., 2008. Calcium-phosphate levels and cardiovascular disease in community-dwelling adults: the atherosclerosis risk in communities (aric) study. Am. Heart J. 156, 556-563.

Gangoiti, M.V., Cortizo, A.M., Arnol, V., Felice, J.I., McCarthy, A.D., 2008. Opposing effects of bisphosphonates and advanced glycation end-products on 
osteoblastic cells. Eur. J. Pharmacol. 600, 140-147.

Guide of TCaUoLA, 2011. Committee for the Update of the Guide for the Care and Use of Laboratory Animals, 2011 ed. Institute for Laboratory Animal Research; Division on Earth and Life Studies, National Research Council of The National Academies; The National Academic Press, Washington, D.C, p. 242.

Iso, H., Stampfer, M.J., Manson, J.E., Rexrode, K., Hennekens, C.H., Colditz, G.A., Speizer, F.E., Willett, W.C., 1999. Prospective study of calcium, potassium, and magnesium intake and risk of stroke in women. Stroke 30, 1772-1779.

Jia, X., Gu, Y., Groome, L.J., Al-Kofahi, M., Alexander, J.S., Li, W., Wang, Y., 2016. $1,25(\mathrm{OH}) 2 \mathrm{D} 3$ induces placental vascular smooth muscle cell relaxation by phosphorylation of myosin phosphatase target subunit 1Ser507: potential beneficial effects of vitamin D on placental vasculature in humans. Biol. Reprod. 94 (5), 116.

Kiel, D.P., Kauppila, L.I., Cupples, L.A., Hannan, M.T., O'Donnell, C.J., Wilson, P.W., 2001. Bone loss and the progression of abdominal aortic calcification over a 25 year period: the framingham heart study. Calcif. Tissue Int. 68, 271-276.

Koike, S., Yano, S., Tanaka, S., Sheikh, A.M., Nagai, A., 2016. Sugimoto t advanced glycation end-products induce apoptosis of vascular smooth muscle cells: a mechanism for vascular calcification. Int. J. Mol. Sci. 17, 1567.

Laemmli, U.K., 1970. Cleavage of structural proteins during the assembly of the head of bacteriophage t4. Nature 227, 680-685.

Lowry, O.H., Rosebrough, N.J., Farr, A.L., Randall, R.J., 1951. Protein measurement with the folin phenol reagent. J. Biol. Chem. 193, 265-275.

Ma, M., Guo, X., Chang, Y., Li, C., Meng, X., Li, S., Du, Z.X., Wang, H.Q., Sun, Y., 2015 Advanced glycation end products promote proliferation and suppress autophagy via reduction of cathepsin d in rat vascular smooth muscle cells. Mol. Cell Biochem. 403, 73-83.

Marie, P.J., Felsenberg, D., Brandi, M.L., 2011. How strontium ranelate, via opposite effects on bone resorption and formation, prevents osteoporosis. Osteoporos. Int. 22, 1659-1667.

Mary, A., Hénaut, L., Boudot, C., Six, I., Brazier, M., Massy, Z.A., Drüeke, T.B., Kamel, S., Mentaverri, R., 2015. Calcitriol prevents in vitro vascular smooth muscle cell mineralization by regulating calcium-sensing receptor expression. Endocrinology 156, 1965-1974.

McCarthy, A.D., Etcheverry, S.B., Bruzzone, L., Cortizo, A.M., 1997. Effects of advanced glycation end-products on the proliferation and differentiation of osteoblastlike cells. Mol. Cell Biochem. 170, 43-51.

McCarthy, A.D., Etcheverry, S.B., Cortizo, A.M., 1999. Advanced glycation end product-specific receptors in rat and mouse osteoblast-like cells: regulation with stages of differentiation. Acta Diabetol. 36, 45-52.

McCarthy, A.D., Etcheverry, S.B., Bruzzone, L., Lettieri, G., Barrio, D.A., Cortizo, A.M., 2001. Non-enzymatic glycosylation of a type 1 collagen matrix: effects on osteoblastic development and oxidative stress. BMC Cell Biol. 2, 16.

McCarthy, A.D., Etcheverry, S.B., Cortizo, A.M., 2001. Effect of advanced glycation end products on the secretion of insulin-like growth factor-i and its binding proteins: role in osteoblast development. Acta Diabetol. 38, 113-122.

McCarthy, A.D., Molinuevo, M.S., Cortizo, A.M., 2013. Ages and bone ageing in diabetes mellitus. J. Diabetes Metab. 4, 276. http://dx.doi.org/10.4172/21556156.1000276

McCarty, M.F., DiNicolantonio, J.J., 2014. The molecular biology and pathophysiology of vascular calcification. Postgrad. Med. 126, 54-64.

Menini, S., Iacobini, C., Ricci, C., BlasettiFantauzzi, C., Salvi, L., Pesce, C.M., Relucenti, M., Familiari, G., Taurino, M., Pugliese, G., 2013. The galectin-3/rage dyad modulates vascular osteogenesis in atherosclerosis. Cardiovasc Res. 100, $472-480$

Mercer, N., Ahmed, H., McCarthy, A.D., Etcheverry, S.B., Vasta, G.R., Cortizo, A.M., 2004. Age-r3/galectin-3 expression in osteoblast-like cells: regulation by AGEs. Mol. Cell Biochem. 266, 17-24.

Molinuevo, M.S., Cortizo, A.M., Etcheverry, S.B., 2008. Vanadium(iv) complexes inhibit adhesion, migration and colony formation of UMR106 osteosarcoma cells. Cancer Chemother. Pharmacol. 61, 767-773.

Okajima, T., Nakamura, K., Zhang, H., Ling, N., Tanabe, T., Yasuda, T., Rosenfeld, R.G.,
1992. Sensitive colorimetric bioassays for insulin-like growth factor (igf) stimulation of cell proliferation and glucose consumption: use in studies of IGF analogs. Endocrinology 130, 2201-2212.

Owens, G.K., Kumar, M.S., Wamhoff, B.R., 2004. Molecular regulation of vascular smooth muscle cell differentiation in development and disease. Physiol. Rev. 84, 767-801.

Paoletti, R., Corsini, A., Soma, M.R., Bernini, F., 1996. Calcium, calcium antagonists and experimental atherosclerosis. Blood Press Suppl. 4, 12-15.

Ren, X., Shao, H., Wei, Q., Sun, Z., Liu, N., 2009. Advanced glycation end-products enhance calcification in vascular smooth muscle cells. J. Int. Med. Res. 37, 847-854

Rodriguez, A., Fruhbeck, G., Gomez-Ambrosi, J., Catalan, V., Sainz, N., Diez, J. Zalba, G., Fortuno, A., 2006. The inhibitory effect of leptin on angiotensin iiinduced vasoconstriction is blunted in spontaneously hypertensive rats. J. Hypertens. 24, 1589-1597.

Salice, V.C., Cortizo, A.M., Gomez Dumm, C.L., Etcheverry, S.B., 1999. Tyrosine phosphorylation and morphological transformation induced by four vanadium compounds on MC3T3E1 cells. Mol. Cell Biochem. 198, 119-128.

Schmidt, A.M., Hori, O., Brett, J., Yan, S.D., Wautier, J.L., Stern, D., 1994. Cellular receptors for advanced glycation end products. Implications for induction of oxidant stress and cellular dysfunction in the pathogenesis of vascular lesions. Arterioscler. Thromb. 14, 1521-1528.

Somjen, D., Weisman, Y., Kohen, F., Gayer, B., Limor, R., Sharon, O., Jaccard, N., Knoll, E., Stern, N., 2005. 25-hydroxyvitamin D3-1alpha-hydroxylase is expressed in human vascular smooth muscle cells and is upregulated by parathyroid hormone and estrogenic compounds. Circulation 111, 1666-1671.

Steitz, S.A., Speer, M.Y., Curinga, G., Yang, H.Y., Haynes, P., Aebersold, R., Schinke, T. Karsenty, G., Giachelli, C.M., 2001. Smooth muscle cell phenotypic transition associated with calcification: upregulation of cbfa 1 and downregulation of smooth muscle lineage markers. Circ. Res. 89, 1147-1154.

Suga, T., Iso, T., Shimizu, T., Tanaka, T., Yamagishi, S., Takeuchi, M., Imaizumi, T., Kurabayashi, M., 2011. Activation of receptor for advanced glycation end products induces osteogenic differentiation of vascular smooth muscle cells. J. Atheroscler. Thromb. 18, 670-683.

Svanstrom, H., Pasternak, B., Hviid, A., 2014. Use of strontium ranelate and risk of acute coronary syndrome: cohort study. Ann. Rheum. Dis. 73, 1037-1043.

Tanikawa, T., Okada, Y., Tanikawa, R., Tanaka, Y., 2009. Advanced glycation end products induce calcification of vascular smooth muscle cells through rage/p38 mapk. J. Vasc. Res. 46, 572-580.

Tolosa, M.J., Chuguransky, S.R., Sedlinsky, C., Schurman, L., McCarthy, A.D. Molinuevo, M.S., Cortizo, A.M., 2013. Insulin-deficient diabetes-induced bone microarchitecture alterations are associated with a decrease in the osteogenic potential of bone marrow progenitor cells: preventive effects of metformin. Diabetes Res. Clin. Pract. 101, 177-186.

Traber, M.G., Stevens, J.F., 2011. Vitamins C and E: beneficial effects from a mechanistic perspective. Free Radic. Biol. Med. 51, 1000-1013.

Tukaj, S., Trzonkowski, P., Tukaj, C., 2012. Regulatory effects of 1,25-dihydroxyvitamin D3 on vascular smooth muscle cells. Acta Biochim. Pol. 59, 395-400.

Wang, X., Li, X., Shen, X., Agrawal, C.M., 2003. Age-related changes of noncalcified collagen in human cortical bone. Ann. Biomed. Eng. 31, 1365-1371.

Yan, S.D., Schmidt, A.M., Anderson, G.M., Zhang, J., Brett, J., Zou, Y.S., Pinsky, D. Stern, D., 1994. Enhanced cellular oxidant stress by the interaction of advanced glycation end products with their receptors/binding proteins. J. BiolChem 269, 9889-9897.

Yu, J., Tang, J., Li, Z., Sajjan, S., O'Regan, C., Modi, A., Sazonov, V., 2015. History of cardiovascular events and cardiovascular risk factors among patients initiating strontium ranelate for treatment of osteoporosis. Int. J. Womens Health 7 913-918.

Zimmermann, E.A., Schaible, E., Bale, H., Barth, H.D., Tang, S.Y., Reichert, P., Busse, B. Alliston, T., Ager 3rd, J.W., Ritchie, R.O., 2011. Age-related changes in the plasticity and toughness of human cortical bone at multiple length scales. Proc. Natl. Acad. Sci. U. S. A. 108, 14416-14421. 